\title{
Bilateral Spontaneous Pneumothorax
}

\author{
Hind Bakkal ${ }^{1}$, Hanane Benjelloun ${ }^{2}$, Nahid Zaghba ${ }^{3}$, Najiba Yassine ${ }^{4}$
}

${ }_{1}^{1}$ Résidente en pneumologie, Service des maladies respiratoires du CHU Ibn Rochd, Casablanca, Marocco
${ }^{2}$ Professeur de pneumologie, Service des maladies respiratoires du CHU Ibn Rochd, Casablanca, Marocco
${ }^{3}$ Professeur de pneumologie, Service des maladies respiratoires du CHU Ibn Rochd, Casablanca, Marocco
${ }^{4}$ Professeur de pneumologie et chef de service, Service des maladies respiratoires du CHU Ibn Rochd, Casablanca, Marocco

DOI: $10.36347 /$ sjmcr.2020.v08i08.009

| Received: 03.07.2020 | Accepted: 24.07.2020 | Published: 13.08.2020

*Corresponding author: Bakkal Hind

Abstract

Original Research Article

Pneumothorax is an emergency therapeutic diagnostic whose bilaterality represents a severity character. The Spontaneous bilateral pneumothorax is rare but remains potentially fatal. According to Casablanca Hospital Center pneumology department, we have reported seven cases during the last six years representing $3 \%$ of total spontaneous pneumothorax patients and predominated by women gender at 31.2 years average age. Bilateral pneumothorax was primitive for one case. For the remaining six cases, it was a secondary of an asthma attack, COPD, miliary tuberculosis, cystic lung and revealed a carcinoid tumor and secondary to diffuse interstitial pneumonitis in the fibrosis stage. Facing such emergency situation, fast handling ware adopted using bilateral thoracic drain for three patients and unilateral one for three other patients. Where a bilateral pleural detachment was less than $2 \mathrm{~cm}$, a rest and an oxygen therapy with close monitoring was recommended. Surgery was advocated to avoid recurrency but was done for two patients. Three patients died while the other patients have progressed well.

Keywords: pneumothorax spontaneous; bilateral; thoracic drainage; management; evolution.

Copyright @ 2020: This is an open-access article distributed under the terms of the Creative Commons Attribution license which permits unrestricted use, distribution, and reproduction in any medium for non-commercial use (NonCommercial, or CC-BY-NC) provided the original author and source are credited.

\section{INTRODUCTION}

Spontaneous bilateral pneumothorax is defined by the concomitant occurrence of pneumothorax in both hemithoraxes. It is a diagnosis and therapeutic emergency that can be life-threatening. It is rare, usually caused by chest trauma, but it can be spontaneous or iatrogenic. Our study's aim is to describe the epidemiological, etiological, clinical, therapeutic and progressive aspects of bilateral pneumothorax cases identified in our pneumology department. The pneumothorax early diagnosis and treatment is of great importance for patients' prognosis.

\section{Patients and Methods}

It is a descriptive, analytical and retrospective study of seven cases admitted during 6 years period, from January 2014 to June 2020. We selected the files of patients hospitalized for pneumothorax and we chose those with bilateral pneumothorax. An operating sheet was established to collect data from these patients.

\section{RESUlTS}

We collected seven cases of bilateral pneumothorax out of the 230 cases of spontaneous pneumothorax admitted in our department between January 2014 and June 2020, i.e. a prevalence of 3\%. We noted female predominance (56\%) and an average age of 31.2 years with extremes ranging from 18 to 50 years. Only one patient was smoking, another poorly monitored for asthma. Two patients were known to be dyspneic with exertion before the recent episode and one patient had unilateral pneumothorax history drained three years earlier.

All of our patients showed out bilateral stabbing chest pain and sudden dyspnea. Bilateral pneumothorax was poorly tolerated in five patients. The clinical check up underlined a bilateral air effusion syndrome in all cases associated with subcutaneous emphysema in three patients.

All of the patients had a correct body mass index except for one thin patient. Elastopathy Signs were absent. In two patients, bilateral pneumothorax showed out while they were hospitalized in our department for a spontaneous unilateral pneumothorax (on miliary tuberculosis ground in the first case and pulmonary fibrosis in the second one). 
For the bilateral pneumothorax aspect, thoracic imagery had revealed miliary aspect in one case, cystic lung, diffuse interstitial pneumonitis at the fibrosis stage, right proximal tumor process, emphysematous lung and pneumomediastinum in one case each.

Pneumothorax's management in these patients was fast and urgent. Bilateral thoracic drainage was performed in three cases and on one side with contralateral exufflations in three other cases. One patient with bilateral pneumothorax with bilateral detachment of less than $2 \mathrm{~cm}$ was on rest with oxygen therapy.

Spontaneous bilateral pneumothorax was primary in one case. It was secondary to asthma exacerbation, a post-smoking emphysema bubble rupture, a miliary tuberculosis, revealing a typical carcinoid tumor, a cystic lung and a diffuse interstitial pneumonia at the fibrosis stage in one case each. Patients with good course were referred after treatment of the recent episode to the thoracic surgery department to ensure one side to avoid bilateral recurrence.

Three deaths were deplored for respiratory distress in patients with pulmonary fibrosis, cystic lung and miliary tuberculosis.

The outcome was good in the other cases for which pleural decortication was indicated to avoid a possible recurrence which could be life-threatening. This was associated with excision of emphysema bubble and carcinoid tumor in one case each.

Two patients, one with asthma and the other with primary bilateral pneumothorax, refused treatment.

No recurrence after SBP treatment was noted in our series with a 6-year follow-up. The clinical data of the seven patients with spontaneous bilateral pneumothorax treated in our department during the study period are summarized in Table- 1 .

Table-1: Clinical, therapeutic and progressive characteristics of patients treated in our department for bilateral spontaneous pneumothorax

\begin{tabular}{|c|c|c|c|c|c|}
\hline Age & sex & Clinic & Underlying affection & pneumothorax Treatement & Evolution \\
\hline 45 & $\mathrm{~F}$ & stabbing chest pain + dyspnea & $\begin{array}{l}\text { Interstitial lung } \\
\text { disease in the fibrosis } \\
\text { stage }\end{array}$ & $\begin{array}{l}\text { Oxygenotherapy + bilateral } \\
\text { drainage }\end{array}$ & Death \\
\hline 20 & $\mathrm{~F}$ & stabbing chest pain + dyspnea & Kystic lung & $\begin{array}{l}\text { Oxygenotherapy+ bilateral } \\
\text { drainage }\end{array}$ & Death \\
\hline 25 & $\mathrm{M}$ & $\begin{array}{l}\text { stabbing chest }+ \\
\text { subcutaneous emphysema }\end{array}$ & Asthma & Oxygenotherapy + left Drainage & good \\
\hline 18 & $\mathrm{M}$ & stabbing chest pain & Primitif & $\begin{array}{l}\text { Oxygenotherapy + left Drainage } \\
+ \text { right exuflation. }\end{array}$ & good \\
\hline 50 & $\mathrm{M}$ & $\begin{array}{l}\text { stabbing chest pain }+ \\
\text { subcutaneous emphysema }\end{array}$ & BPCO & $\begin{array}{l}\text { Oxygenotherapy at low flow } \\
+ \text { left Drainage + right exuflation. }\end{array}$ & good \\
\hline 23 & $\mathrm{~F}$ & stabbing chest pain + dyspnea & tuberculous Miliary & $\begin{array}{l}\text { Oxygenotherapy + bilateral } \\
\text { drainage }\end{array}$ & Death \\
\hline 38 & $\mathrm{~F}$ & $\begin{array}{l}\text { stabbing chest pain }+ \\
\text { subcutaneous emphysema }\end{array}$ & $\begin{array}{l}\text { typic carcinoide } \\
\text { Tumor }\end{array}$ & Oxygenotherapy +rest & good \\
\hline
\end{tabular}

\section{DiSCUSSION}

Spontaneous bilateral pneumothorax (SBP) is a rare affection whose prevalence varies according to studies from 1 to $20 \%$ of all pneumothorax [1-4]. In our series, its prevalence was $3 \%$. This result is consistent with that of rabat study in which the prevalence of PBS in all patients with spontaneous pneumothorax was $3 \%$ [5]. The male sex is predominant in the literature [2, 3]. We collected four women and three men. Bilateral pneumothorax mainly affects young adults. The average age in our series was 31.2 years with extremes ranging from 18 to 50 years. Other studies have noted younger age of $20.9+/-4.7$ years [3].

BPCO is the main risk factor for SBP onset, following the post-smoking emphysema bubbles rupture $[1,3,4,6]$.
Other underlying pathologies are found in $58 \%$ to $68 \%$ of cases. It can be a malignant tumor, miliary tuberculosis, Ehlers-Danlos syndrome, histiocytosis X [1, 2], Marfan syndrome, Alport syndrome, anorexia nervosa, and multiple myeloma . Intravenous drug use has also been reported [6]. In women, few rare cases of catamenial SBP and in the context of lymphangioleiomyomatosis have been described $[2,7$, 8].

Eighty-six percent of our patients had an underlying pathology including asthma, post-smoking emphysema, miliary tuberculosis, carcinoid tumor, cystic lung and diffuse interstitial lung disease at the fibrosis stage. A low body mass index also represents a risk factor [1, 3, 4]. 
Sudden stabbing chest pain is the main symptom as well as dyspnea. Subcutaneous emphysema and / or pneumomediastinum may be together with SBP but it is similar to that of unilateral pneumothorax [2]. In our series, subcutaneous emphysema was present in the three cases, one of which was associated with pneumomediastinum.

The clinical examination underlined at the level of the two hemithorax, reduced thoracic amplification, a tympanism on percussion, an abolition of the transmission of vocal vibrations on palpation and a vesicular murmurs abolition on auscultation. However, if the amount of air in the pleural cavity is small, the physical examination may be normal [1]. The chest X-ray confirms diagnosis by highlighting the bilateral pneumothorax. The chest scanner is performed in case of doubtful diagnosis and to look for an underlying pathology which may explain the PBS occurrence.

Clinical tolerance is very varied, ranging from symptoms' absence to cardiopulmonary insufficiency [2]. Over two thirds $(71.5 \%)$ of our patients presented with poorly tolerated bilateral pneumothorax.

Simultaneous bilateral pneumothorax treatment consists first of all in resolving the acute episode with pleural drainage and then performing definitive surgery, according to the international experts groups recommendations (ACCP; BTS) to avoid recurrences $[1,2,4,9]$. Indeed, given the high rate of recurrence reported in studies (44-45\%) [6], it is reasonable to try surgical treatment at least on one side, as early as possible [1-4]. This consists of a pleurodesis or pleurectomy to avoid bilateral recurrence [1-4].

The most common surgical practice currently in these patients is bilateral multi-assisted thoracoscopic surgery (VATS). In addition, to minimize the surgical impact, centers have currently adopted the uniportal subxiphoid VATS technique with the possibility of accessing the two pleural cavities using a single incision, allowing postoperative pain reduction and quality of life's recovery [10].

Bilateral pneumothorax prognosis is good but remains linked to timely treatment and the underlying lung condition. Indeed, mortality varying between 1 and $4 \%$ has been reported in the literature. It is higher ( 1 to $17 \%$ ) in the case of chronic obstructive pulmonary disease, and up to $75 \%$ in the case of HIV infection [1, $6]$.

In our series, the three cases of death reported occurred in pathological lungs: pulmonary fibrosis, cystic lung and miliary tuberculosis. The other four patients progressed well. No recurrence after SBP treatment was noted in our patients with 6-year followup.

\section{CONCLUSION}

Spontaneous bilateral pneumothorax is a rare but serious pathology. Bilaterality is pneumothorax's severity factor, urgent and adequate management of which improves the patients prognosis. It mainly concerns young people and is often linked to an underlying pulmonary pathology, the severity of which is correlated with poor prognosis. Thoracic drainage is the best short-term therapeutic option.

\section{Conflict of Interest: None}

\section{REFERENCES}

1. Kewcharoen J, Morris P, Kanitsoraphan C, La H, Sriratanaviriyakul N. Simultaneous Bilateral Primary Spontaneous Pneumothorax: A Case Report and a Review of the Literature. Case reports in pulmonology. 2019 Jan 27;2019.

2. Graf-Deuel E, Knoblauch A. Simultaneous bilateral spontaneous pneumothorax. Chest. 1994 Apr 1;105(4):1142-6.

3. Lee SC, Cheng YL, Huang CW, Tzao C, Hsu HH, Chang H. Simultaneous bilateral primary spontaneous pneumothorax. Respirology. 2008 Jan;13(1):145-8.

4. Huang TW, Cheng YL, Tzao C, Hung C, Hsu HH, Chen JC, Lee SC. Factors related to primary bilateral spontaneous pneumothorax. The Thoracic and Cardiovascular Surgeon. 2007 Aug;55(05):310-2.

5. Habibi B, Achachi L, Hayoun S, Raoufi M, Herrak L, El Ftouh M. La prise en charge du pneumothorax spontané: à propos de 138 cas. The Pan African Medical Journal. 2017;26:152.

6. Ríos JH, Alduenda JL, Poblano EE. Neumotórax bilateral espontáneo simultáneo primario. Presentación de un caso y revisión de la bibliografía. Medicina Interna de México. 2005;21(6):486-9.

7. Raphaël O, Blaise D, Maurice K, Kohou-Kone L, Joseph K, N'Guessan E. L'endométriose thoracique : une expérience à propos de 27 cas opérés. Journal de la SFCTCV. 2018; 22.

8. Belliraj L, Ismaili A, Alaoui A, Harmouchi H, Lakranbi M, Serraj M, Ouadnouni Y, Smahi M. La lymphangioléiomyomatose sporadique: cause rare du pneumothorax spontané bilatéral chez la femme jeune. Revue de Pneumologie Clinique. 2018 Dec 1;74(6):497-501.

9. MacDuff A, Arnold A, Harvey J. Management of spontaneous pneumothorax: British Thoracic Society pleural disease guideline 2010. Thorax. 2010 Aug 1;65(Suppl 2):ii18-31.

10. Matthew F, Karunanantham J, Jason MA, Serena C, Shruti J, Adam P. Approche subxiphoïde pour pneumothorax bilatéral spontané: un rapport de cas. Journal de chirurgie visualisée. Journal Vis Surg. 2017; 3:146. 